\title{
Article \\ Design of a SIW Variable Phase Shifter for Beam Steering Antenna Systems
}

\author{
Sara Salem Hesari * and Jens Bornemann ${ }^{(D)}$ \\ Department of Electrical and Computer Engineering, University of Victoria, Victoria, BC V8W 2Y2, Canada; \\ jbornema@ece.uvic.ca \\ * Correspondence: ssalem@uvic.ca; Tel.: +1-250-721-8989 (ext. 2769)
}

Received: 26 July 2019; Accepted: 8 September 2019; Published: 11 September 2019

\begin{abstract}
This paper proposes a new beam steering antenna system consisting of two variable reflection-type phase shifters, a $3 \mathrm{~dB}$ coupler, and a $90^{\circ}$ phase transition. The entire structure is designed and fabricated on a single layer of substrate integrated waveguide (SIW), which makes it a low loss and low-profile antenna system. Surface mount tuning varactor diodes are chosen as electrical phase control elements. By changing the biasing voltage of the varactor diodes in the phase shifter circuits, the far-field radiation pattern of the antenna steers from $-25^{\circ}$ to $25^{\circ}$. The system has a reflection coefficient better than $-10 \mathrm{~dB}$ for a $2 \mathrm{GHz}$ bandwidth centered at $17 \mathrm{GHz}$, a directive radiation pattern with a maximum of $10.7 \mathrm{~dB}$ gain at the mid-band frequency, and cross polarization better than $20 \mathrm{~dB}$. A prototype is fabricated and measured for design verification. The measured far-field radiation patterns, co and cross polarization, and the reflection coefficient of the antenna system agree with simulated results.
\end{abstract}

Keywords: beam steering antenna system; SIW technology; variable phase shifter; varactor diodes

\section{Introduction}

Beam steering antenna systems have become progressively popular in modern communications. Transferring and receiving high rate data, scanning a large scale of the atmosphere, having compact structures with minimum losses-all are attributed to and achieved through electrical beam steering antenna systems.

The main components in designing a beam steering antenna system are the phase shifters. Phase shifting in an antenna array can be achieved by using different methods. Included are variable phase shifters equipped with varactor diodes [1], PIN diode phase shifters (which have three types: switched line, loaded line, and reflection) [2], a Nolen matrix [3] or a Butler matrix [4] for constant phase shifts, complementary split ring resonators (CSRRs) [5], a tunable band-pass filter as phase shifter [6], a liquid crystal miniaturized phase shifter [7], some innovative vector-sum phase shifters by using CMOS technology [8,9], and a continuously steered beam in a range of $\pm 45^{\circ}$ through an array of vector controllers [10], to name only a few.

Substrate integrated waveguide (SIW) has recently attracted a lot of attention because of its compactness, low loss, and its promising performance in mm-wave and microwave applications. Therefore, researchers started to not only use this technology for passive components, but also in active component areas like variable phase shifters. Reference [1] introduces two SIW phase shifters. First, an inline phase shifter using a varactor diode with a phase shift of $25^{\circ}$. Secondly, a $180^{\circ}$ SIW reflection-type phase shifter including a biasing circuit, four varactor diodes, and two open stubs. By changing the loading of a waveguide, a controllable phase shifter is achieved in [11]. The phase shift is controlled by four PIN diodes inserted in the substrate, and a maximum phase shift of $45^{\circ}$ is obtained. An EM-wave coupling technique is proposed for achieving a wider bandwidth in a two layer 
SIW phase shifter design [12], and a phase shift of up to $180^{\circ}$ is obtained by using eight PIN diodes. The combination of a $90^{\circ}$ hybrid consisting of two waveguide layers and four varactor diodes, two on top and two on the bottom, results in a four layer structure. This phase shifter has nearly $360^{\circ}$ phase variation [13]. The authors of [14] propose an SIW K-band phase shifter with minimum $105^{\circ}$ phase tuning range and $4 \mathrm{~dB}$ insertion loss by using varactor diodes as tuning elements. Note that since varactor diodes and their connecting transitions add losses to the circuit and also affect the radiation pattern of the antenna due to radiations from the connecting microstrip lines, the use of fewer varactor diodes is desirable.

A $2.8 \mathrm{GHz}$ to $4.8 \mathrm{GHz}$ beam steering microstrip antenna for radar applications is introduced in [15]. Beam steering is achieved with a pair of PIN diodes connecting the stubs to the ground and changing the state between On and Off. A single narrow bandwidth patch antenna is proposed in [5] which steers the beam by using complementary split ring resonators (CSRRs) as part of the ground plane. The antenna with double CSRR loading is able to steer the beam from $-51^{\circ}$ to $48^{\circ}$. A scan range up to $16^{\circ}$ is obtained with an integrated $95 \mathrm{~mm}$ diameter lens antenna [16] in E-band. The beam is directed to different angles by switching between the feed elements of the array. Reference [2] presents a reconfigurable beam steering system comprising four patch antennas, three power dividers, and four phase shifters. A switched line PIN diode phase shifter is used for directing the beam between $-30^{\circ}$ to $30^{\circ}$. Reference [17] introduces a new approach to generate beam steering antenna systems without using phase shifters. A $4 \times 4$ planar circularly polarized spiral antenna array is designed and verified in a spherical coordinate system. As $\phi$ changes from 0 to $2 \pi$, the phase of the $\mathrm{CP}$ antenna's co-pol radiation will change by $2 \pi$, while $r$ and $\theta$ remain constant. A single layer SIW version of a $4 \times 4$ Butler matrix system is presented in [18], achieving scanning angles of $\pm 25^{\circ}$. A broadband beam steering antenna for 5G applications is introduced in [4]. This design includes a $4 \times 4$ Butler matrix which applies progressive phase shift between microstrip antenna elements. Since a Butler matrix has some constant phase differences at the output, a signal can be directed only to some specific angles. Reference [6] demonstrates a new method of using band-pass filters as phase shifters or tunable filters by using coupled microstrip resonators loaded with a varactor diode in the filter structure. A $1 \times 4$ steerable dielectric resonator antenna array at $C / X$ band is presented in [19]. Inkjet-printed barium strontium titanate (BST) thick-film is applied as phase shifters. Integrated metal-insulator-metal varactors are used for tuning the phase. This antenna system achieves $\mathrm{a} \pm 30^{\circ}$ beam steering range.

Firstly, this paper proposes an SIW Ku-band variable phase shifter. This phase shifter is a combination of a $3 \mathrm{~dB}$ coupler with an isolation better than $30 \mathrm{~dB}$ at the mid-band frequency of $17 \mathrm{GHz}$ and $22 \mathrm{~dB}$ in the entire operating bandwidth, with two varactor diodes as electrical phase control elements. Then, an antenna array consisting of two Vivaldi antennas is introduced for designing a beam steering antenna system. The proposed beam steering system is designed on a single SIW layer which makes it a low-profile structure with minimum losses. The system has a $2 \mathrm{GHz}$ bandwidth with a reflection coefficient better than $-10 \mathrm{~dB}$ between $16 \mathrm{GHz}$ and $18 \mathrm{GHz}$ and $50^{\circ}$ controllable beam steering capability. Therefore, the design criteria consisting of reflection coefficient better than $10 \mathrm{~dB}$, $10 \mathrm{~dB}$ gain, $50^{\circ}$ scanning angle with cross polarization better than $20 \mathrm{~dB}$, which are normally required for tracking systems and other possible scanning applications, are achieved successfully.

\section{SIW Variable Phase Shifter}

SIW phase shifters have the advantages of being compact, low loss, and planar which make them suitable for integration with other components on a single layer. Phase shifters are critical components in the mm-wave and microwave area for applications like phased array systems in radio astronomy, and beam steering systems for tracking applications in wireless and satellite communications. Phase shifters divide into two main groups: Fixed phase shifters and variable phase shifters. This paper's focus is on the design of a variable SIW phase shifter. 


\subsection{SIW 3-dB Coupler}

A hybrid coupler with high isolation and $3 \mathrm{~dB}$ coupling is designed on RT/duroid 6002 substrate with relative permittivity of 2.94, thickness of $h=0.508 \mathrm{~mm}$, and loss tangent of 0.0012 [20]. The component is designed and simulated in CST Microwave Studio 2018. Figure 1 presents the SIW $3 \mathrm{~dB}$ coupler structure. The required coupling and isolation are achieved by optimizing the length of the gap in the middle, the location of the vias on both sides, and also the middle vias. As shown in Figure $2 \mathrm{a}$, this design has a reflection coefficient better than $-22 \mathrm{~dB}$ in the entire frequency range. It has an isolation between the adjacent ports of higher than $30 \mathrm{~dB}$ at mid-band frequency and $3 \mathrm{~dB}$ power division between $16 \mathrm{GHz}$ and $18 \mathrm{GHz}$. Figure $2 \mathrm{~b}$ demonstrates that the transmission coefficient, when including dielectric and metallic losses in the analysis, amounts to an insertion loss of less than $0.5 \mathrm{~dB}$.

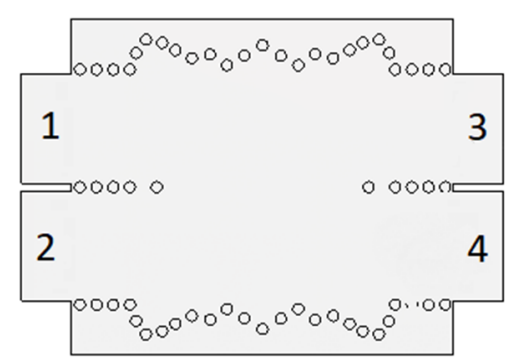

Figure 1. Substrate integrated waveguide $3 \mathrm{~dB}$ coupler.

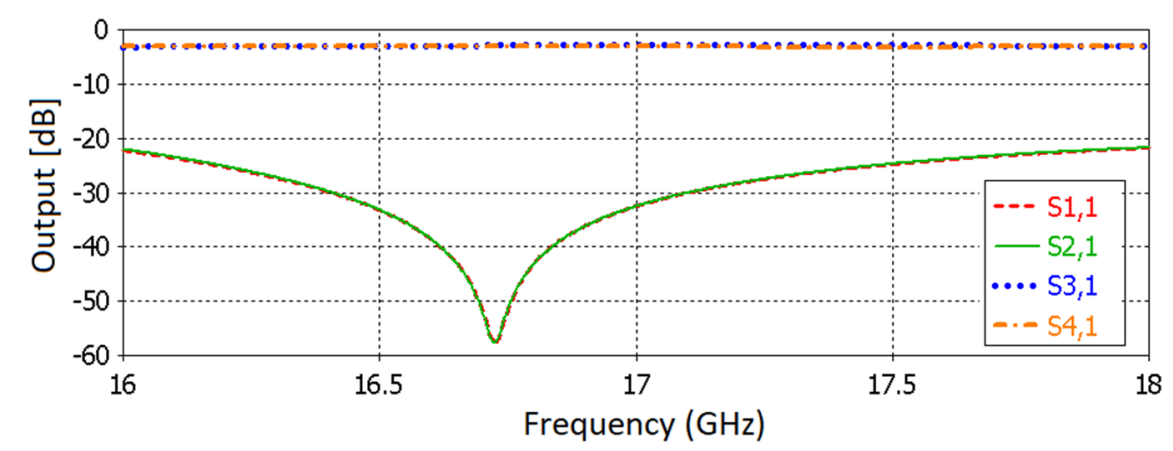

(a)

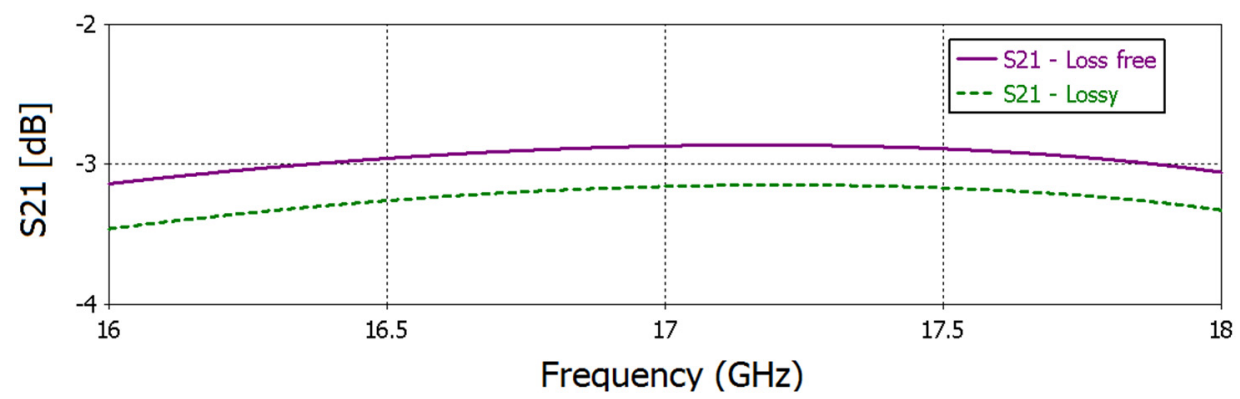

(b)

Figure 2. Scattering parameters of the $3 \mathrm{~dB}$ coupler, (a) ideal, (b) $\mathrm{S}_{21}=\mathrm{S}_{31}$ with dielectric and metal losses included compared to lossless analysis.

\subsection{SIW Variable Phase Shifter}

A reflection-type variable phase shifter is designed in this section, which consists of an SIW 3-dB coupler and the biasing circuit for the varactor diodes. Figure 3 shows the structure and parameters of the phase shifter. The phase shifter parameters including the coupler are designed based on the theoretical analysis introduced in [21]. The reader is referred to [21] for details. The waveguide width is designed based on the cutoff frequency [14], and the SIW width is defined by using the proposed 
formula in [22]. The $d / p$ ratio is chosen as 0.65 to have minimum wave leakage in the SIW circuit. Table 1 presents the phase shifter's dimensions.

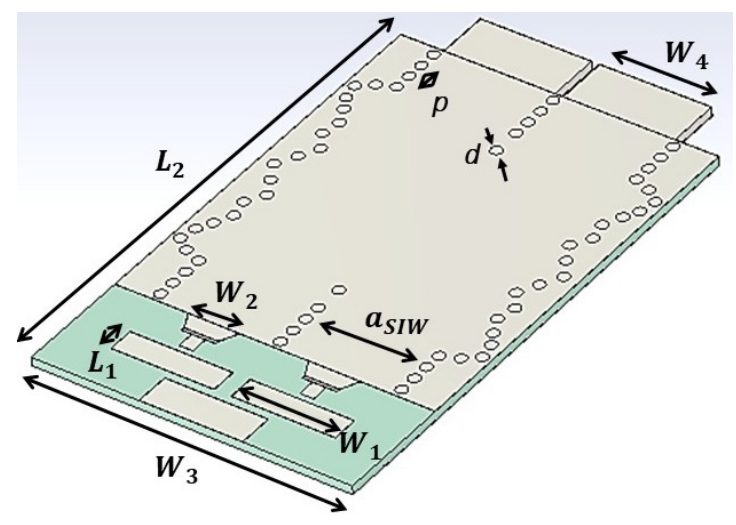

Figure 3. SIW variable phase shifter structure and parameters.

Table 1. Dimensions of the SIW variable phase shifter.

\begin{tabular}{cccc}
\hline Parameter & Dimension $(\mathbf{m m})$ & Parameter & Dimension $(\mathbf{m m})$ \\
\hline$p$ & 1 & $W_{1}$ & 6 \\
$d$ & 0.65 & $W_{2}$ & 3 \\
$L_{1}$ & 1.5 & $W_{3}$ & 18.6 \\
$L_{2}$ & 29.46 & $W_{4}$ & 6.508 \\
$h$ & 0.508 & $a_{S I W}$ & 7 \\
\hline
\end{tabular}

Before applying the varactor diodes to the coupler introduced in Section 2.1, two capacitors are applied to ports 3 and 4 (Figure 1) to analyze the phase variation that can be obtained by this circuit. As revealed in Figure 4, by changing the capacitor value from $0.1 \mathrm{pF}$ to $5 \mathrm{pF}$, a phase variation of about $125^{\circ}$ is obtained. After $5 \mathrm{pF}$, the value of the capacitor is so high that it resembles a short circuit (about $2 \Omega$ impedance), thus the phase variation saturates.

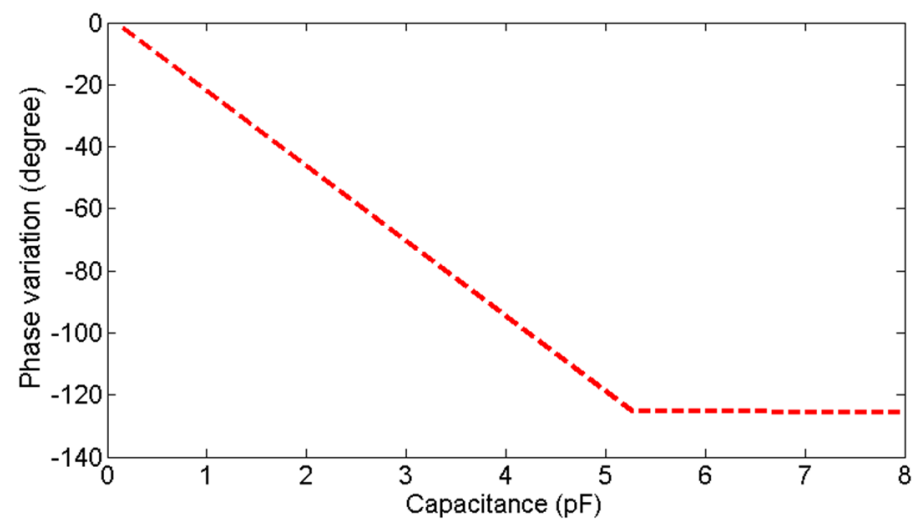

Figure 4. Phase variation of the 3-dB coupler by applying different capacitance values at ports 3 and 4 .

For this design, the silicon hyper abrupt junction varactor diode SMV2201-040LF [23] is chosen, which is specifically designed for wideband applications. For examining the performance of this diode, its equivalent circuit is modeled and analyzed in CST, which is demonstrated in Figure 5. A microstrip-to-SIW transition comprising a $50-\Omega$ microstrip line and a tapered microstrip section as well as two parasitic compensation stubs with width $W_{1}$ and length $L_{1}$ (Figure 3 ) are applied to ports 3 and 4 of the coupler for achieving the required capacitance for a $125^{\circ}$ phase shift. An inductor is inserted between the DC voltage and the varactor diode to provide a quasi-open circuit for the RF 
signal. Table 2 presents the relationship between the output phase of the phase shifter circuit and biasing voltage of the varactor diodes for a single-phase shifter. By increasing the biasing voltage from 0 to $20 \mathrm{~V}$, a nonlinear variation of phase difference between $0^{\circ}$ and $126^{\circ}$ is achieved.

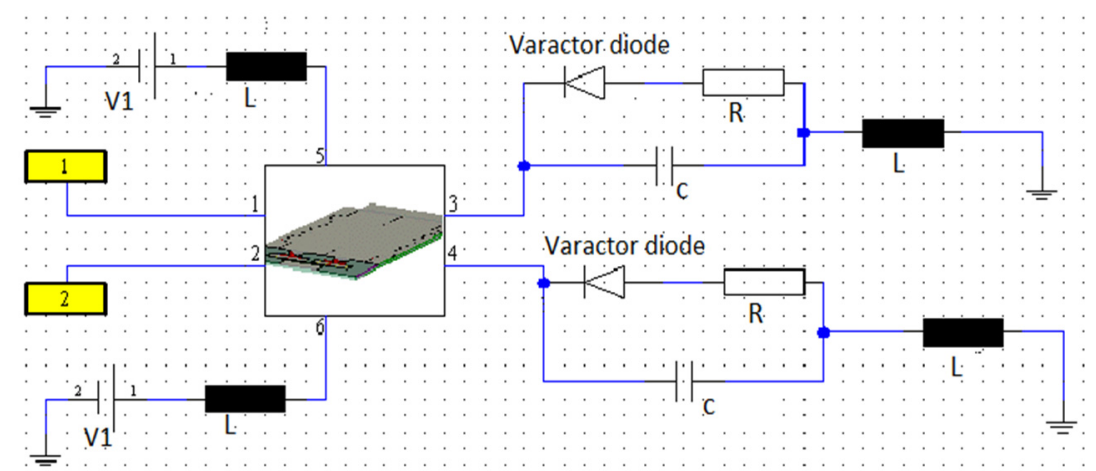

Figure 5. Schematic part of the SIW variable phase shifter and equivalent circuits of the varactor diodes.

Table 2. Phase shifter angle and capacitance as a function of biasing voltage.

\begin{tabular}{ccc}
\hline Voltage $(\mathbf{V})$ & Capacitor $(\mathbf{p F})$ & Phase Shifter Angle (degree) \\
\hline 0 & 2.10 & 0 \\
5 & 0.67 & 45.51 \\
10 & 0.33 & 75.92 \\
15 & 0.26 & 106.34 \\
20 & 0.23 & 126.02 \\
\hline
\end{tabular}

Figures 6-8 demonstrate the performance of the variable phase shifter by applying 0 to $20 \mathrm{~V}$ biasing voltage to the circuit. While applying five different voltages, Figure 6 shows the reflection coefficient of the variable phase shifter which is better than $-15 \mathrm{~dB}$ in all cases between $16 \mathrm{GHz}$ and $18 \mathrm{GHz}$. The phase variation achieved by the equivalent circuit of the varactor diode is demonstrated in Figure 7 and verifies the $120^{\circ}$ phase differences. Figure 8 presents the insertion loss of the proposed phase shifter, which improves from $11 \mathrm{~dB}$ to $3 \mathrm{~dB}$ by increasing the biasing voltage from 0 to $20 \mathrm{~V}$.

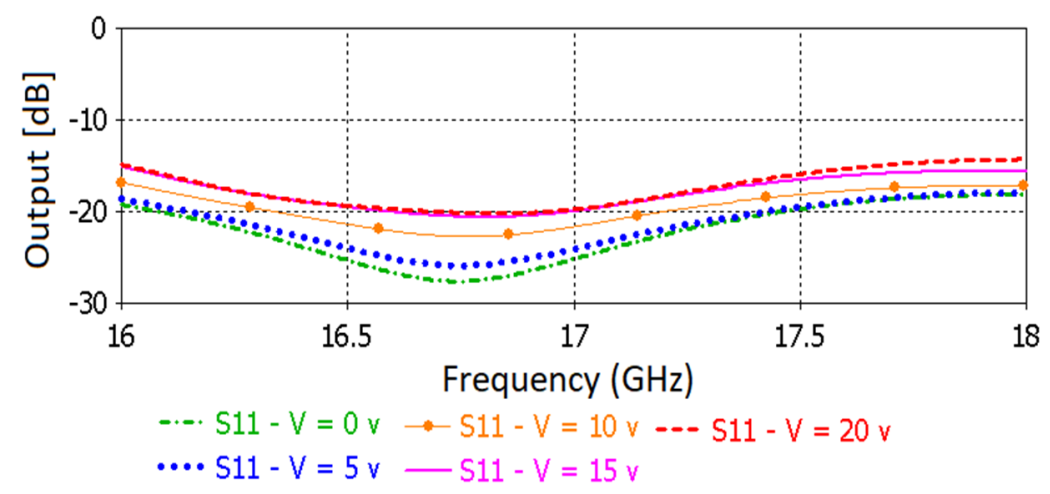

Figure 6. Reflection coefficient of the SIW variable phase shifter for five different biasing voltages. 


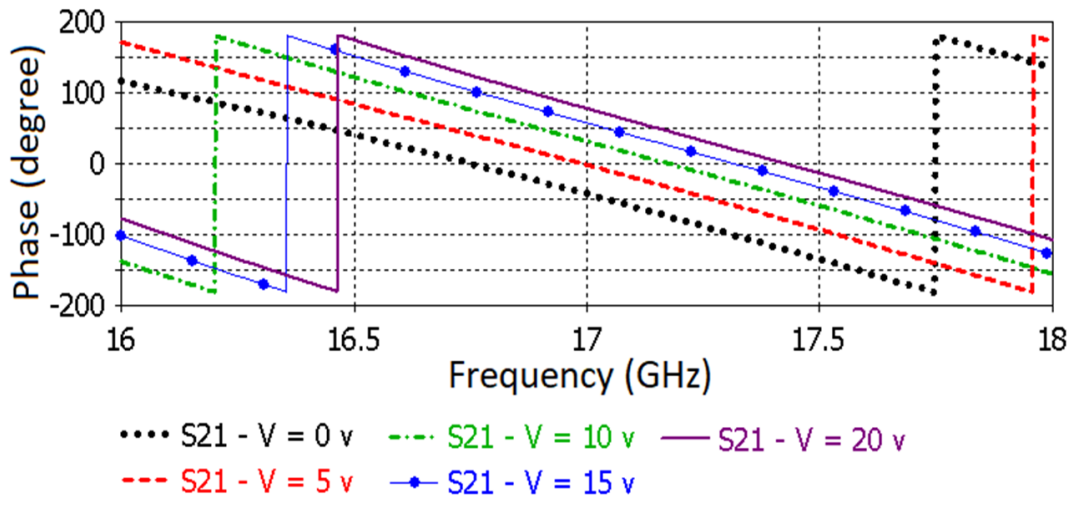

Figure 7. Phase variation of the SIW variable phase shifter for five different biasing voltages.

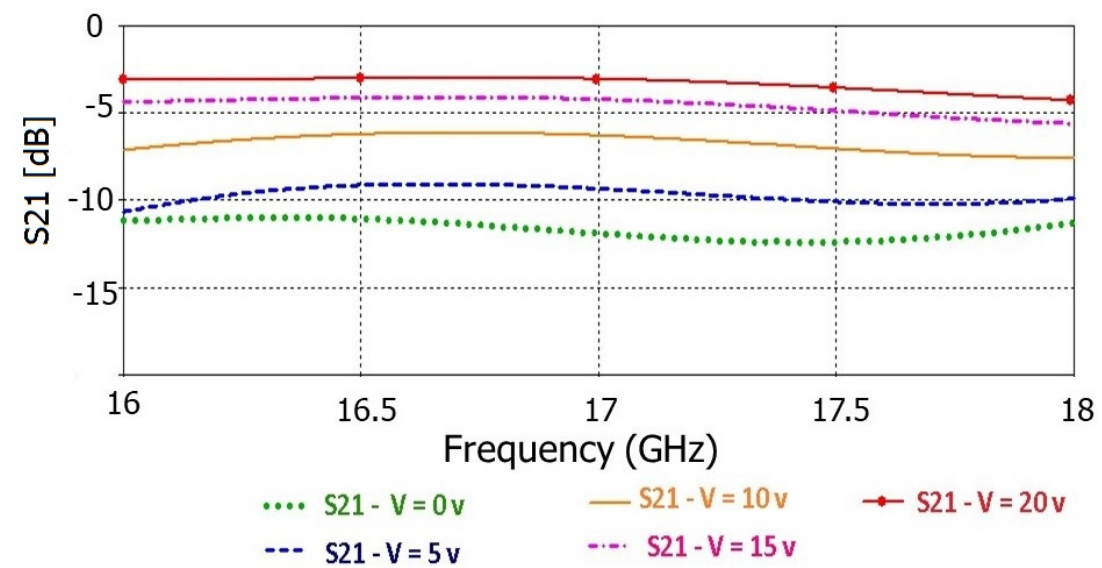

Figure 8. Insertion loss of the SIW variable phase shifter for five different biasing voltages.

\section{SIW Beam Steering Antenna System}

By using electrically variable phase shifters, we are able to change the phase of the signal in any individual antenna element in an array, which consequently steers the far-field radiation pattern of the array in space without the need for any mechanical rotation.

\subsection{Vivaldi Antenna}

An antipodal Vivaldi antenna is employed as the radiating element for this antenna system. It is designed based on the parametric study in [24], and then fine optimized [25] for performance in the required frequency band of $16 \mathrm{GHz}$ to $18 \mathrm{GHz}$. The Vivaldi antenna is horizontally polarized, and vertical polarization is blocked by the comb-like corrugations on two arms of the antenna. Therefore, the corrugations improve cross polarization. The proposed antenna has a wide bandwidth with a reflection coefficient better than $-15 \mathrm{~dB}$ in the entire operating bandwidth, as presented in Figure 9a. Its end-fire radiation pattern with high directivity is displayed in Figure 9b. This single antenna provides about $9.6 \mathrm{~dB}$ gain at mid-band frequency. The proposed Vivaldi antenna has a very directive radiation pattern with $50^{\circ} \mathrm{HPBW}$, which consequently limits the scan range of the beam steering system to about $50^{\circ}$. 


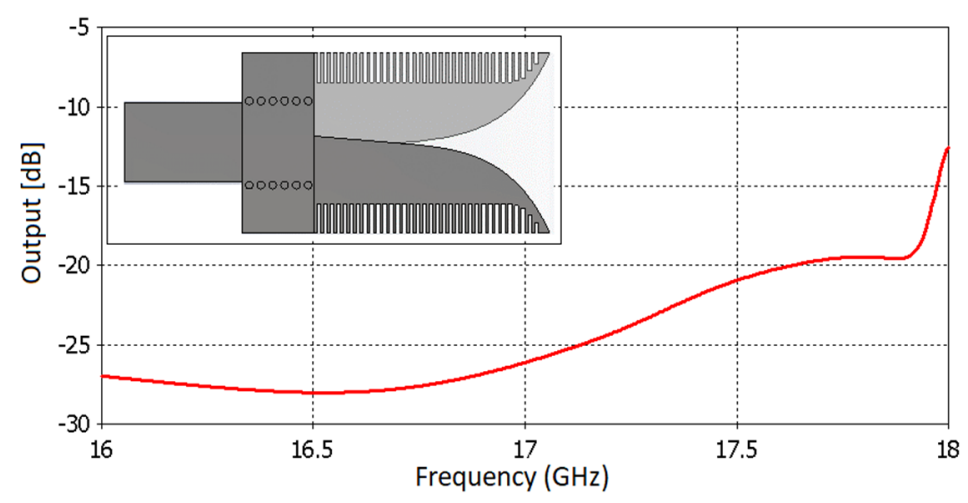

(a)

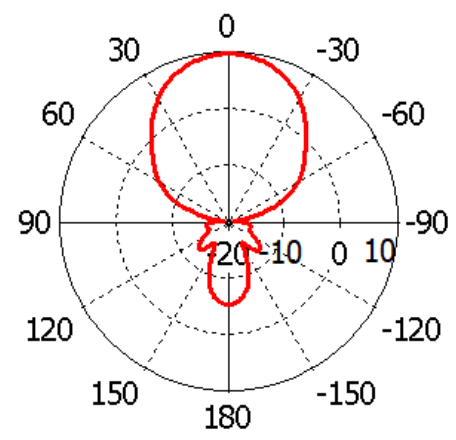

(b)

Figure 9. SIW Vivaldi antenna, (a) reflection coefficient, (b) far-field radiation pattern at $17 \mathrm{GHz}$.

\subsection{Beam Steering Antenna System}

Beam steering is accomplished by applying a progressive phase shift between neighboring elements in an array. The proposed beam steering antenna system includes two variable phase shifters, an antenna array consisting of two Vivaldi antennas, and a $90^{\circ}$ phase transition. A microstrip-to-SIW transition is designed for feeding the antenna system by K-connectors at ports 1 and 2. First, a $50-\Omega$ microstrip line is designed based on principles explained in [26]. Then, it is tapered out for a better match. Figure 10 demonstrates the entire beam steering antenna system.

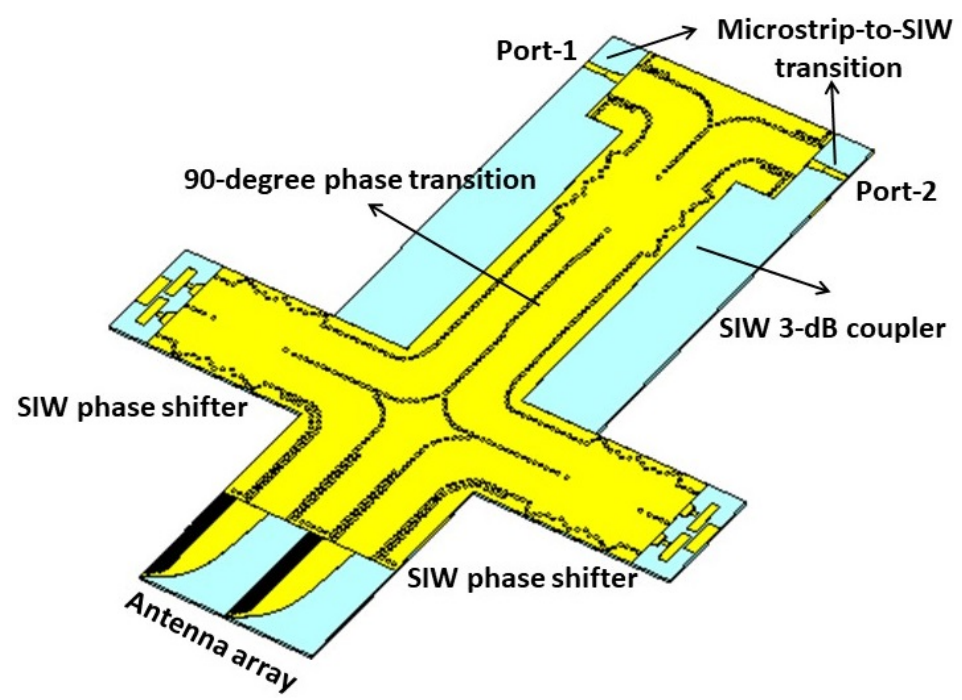

Figure 10. Beam steering antenna system. 
A SIW $90^{\circ}$ phase transition is applied between the 3- $\mathrm{dB}$ coupler and phase shifters. This transition causes $0^{\circ}$ and $180^{\circ}$ phase differences between the input ports of the right and left phase shifter when exciting port 1 and port 2, respectively [27]. Therefore, a $0^{\circ}$ (sum) and $180^{\circ}$ (difference) steering range is obtained by using this transition. Figure 11 displays the electric field distribution in the entire antenna system when port 1 is excited. As exhibited, minimum loss and no wave-leakage through the SIW transitions are accomplished.

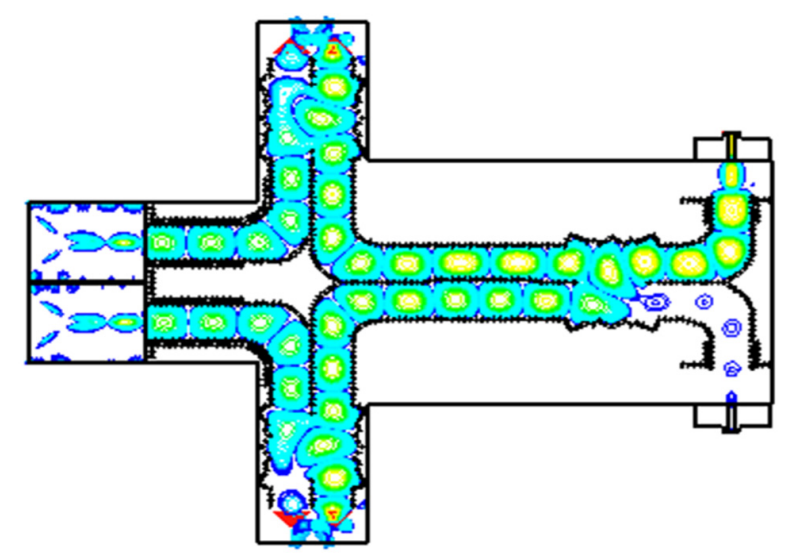

Figure 11. Electric field distribution in SIW beam steering antenna system at $17 \mathrm{GHz}$ when port 1 is excited.

In order to calculate the beam steering range of the system by considering a phase shifter with a maximum of $125^{\circ}$ phase variation, the following formula is used [28]:

$$
\psi=\frac{-360 f}{c}\left(\left[d_{x}+\Delta_{x}\right] \sin \theta \cos \phi+d_{y} \sin \theta \sin \phi\right)
$$

where $\psi$ is the phase shift between the elements, $f$ is the frequency, $c$ is the speed of light, $d_{x}$ and $d_{y}$ are $x$ - and $y$-element spacing, $\Delta_{x}$ is the row offset for a non-rectangular lattice, and $\theta$ and $\phi$ are the beam steering angles.

As revealed in [23], by applying 0 to $20 \mathrm{~V}$ bias to the varactor diode, its capacitance changes between $0.23 \mathrm{pF}$ and $2.1 \mathrm{pF}$. The gain pattern of the beam steering antenna system is presented in Figure 12 at mid-band frequency of $17 \mathrm{GHz}$, while port 1 is excited and port 2 is terminated. As expected by applying the same biasing voltage to both right and left phase shifters, a signal with a $180^{\circ}$ phase difference feeds the Vivaldi antennas which consequently causes a deep null in the broad-sight direction of the antenna.

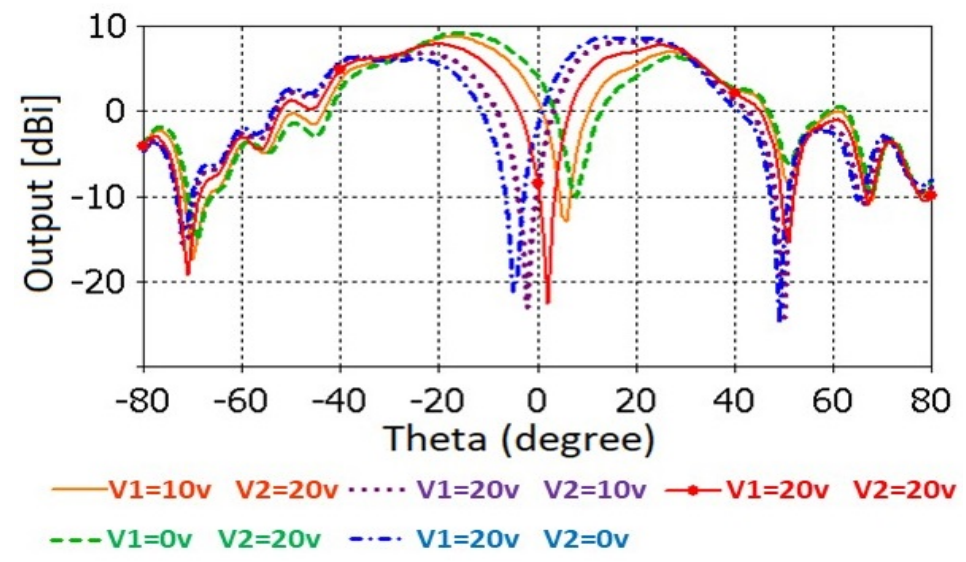

Figure 12. Simulated gain patterns of the beam steering antenna system at $17 \mathrm{GHz}$ for 5 different loadings while port 1 is excited. 
Figure 13 presents the gain pattern of the antenna system for five different loadings when port 2 is excited and port 1 is terminated. Due to the $90^{\circ}$ transition by exciting port 2 , signals go through the SIW phase shifters with $180^{\circ}$ phase differences. Therefore, by applying the same voltage to the right and left phase shifters, another $180^{\circ}$ phase difference is added to the signal which causes a directive radiation pattern in the broad-sight direction of the system.

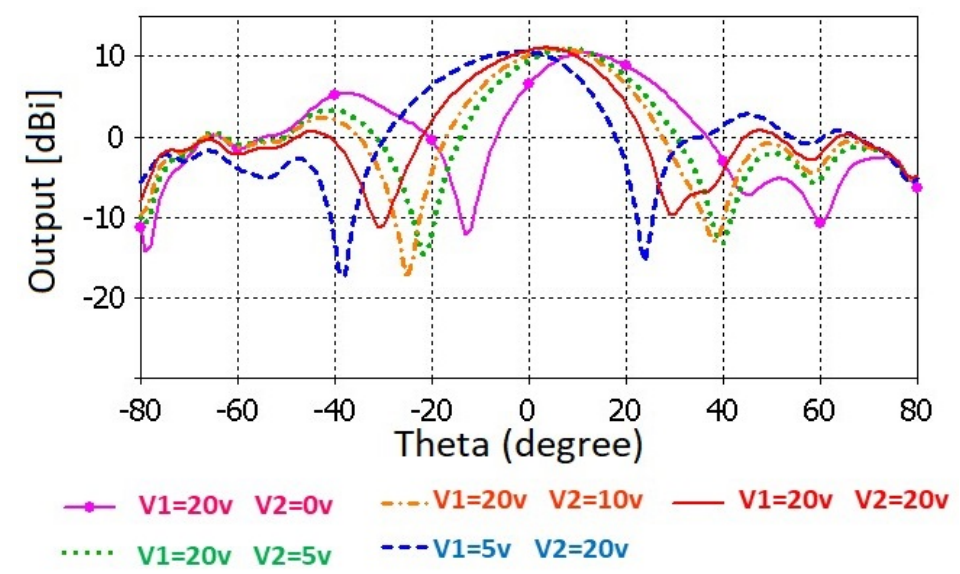

Figure 13. Simulated gain pattern of the beam steering antenna system at $17 \mathrm{GHz}$ for 5 different loadings while port 2 is excited.

By considering the progressive phase shift between the individual antennas by exciting port 1 and port 2 , a beam steering range from $-25^{\circ}$ to $+25^{\circ}$ is obtained, which verifies the calculated value by using Equation (1).

\section{Experimental Results}

The proposed SIW antenna system is fabricated on a single layer of RT/duroid 6002. The top and bottom views of the fabricated prototype and details of the phase shifter circuit are displayed in Figure 14. Two end launch K-connectors are used for exciting the ports. Four varactor diodes are soldered to the board between the microstrip and compensation stubs. Two inductors are placed in series with the varactor diodes and DC voltage supply which can be replaced by chip inductors.

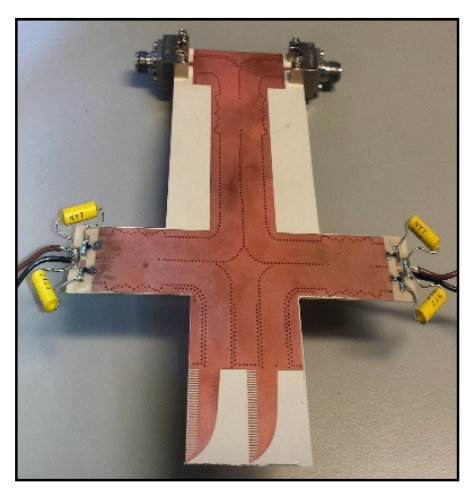

(a)

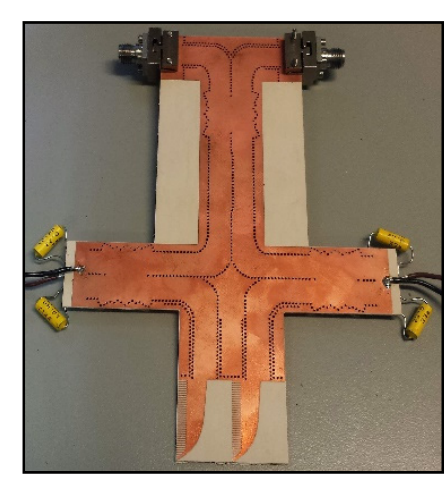

(b)

Figure 14. Cont. 


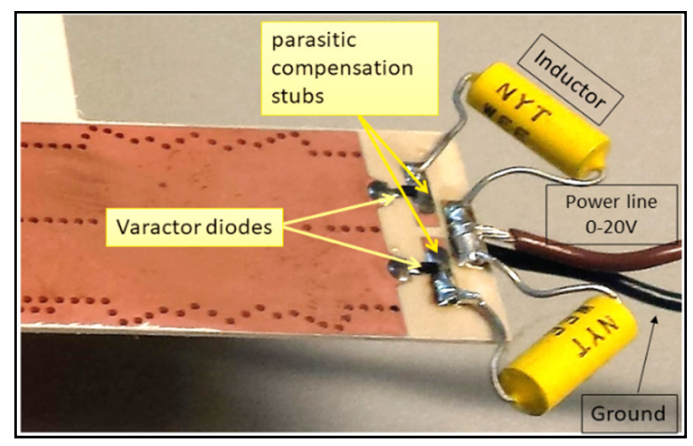

(c)

Figure 14. Beam steering antenna system prototype, (a) top view, (b) bottom view, (c) details of the phase shifter circuit.

For performance verification, the antenna system is measured in a far-field anechoic chamber using an Anritsu 37397C vector network analyzer. Figure 15 presents both simulated and measured reflection coefficients of the beam steering antenna system for ports 1 and 2 . The reflection coefficient is better than $-10 \mathrm{~dB}$ in the entire frequency range, and measurements show a fairly good agreement with simulation results.

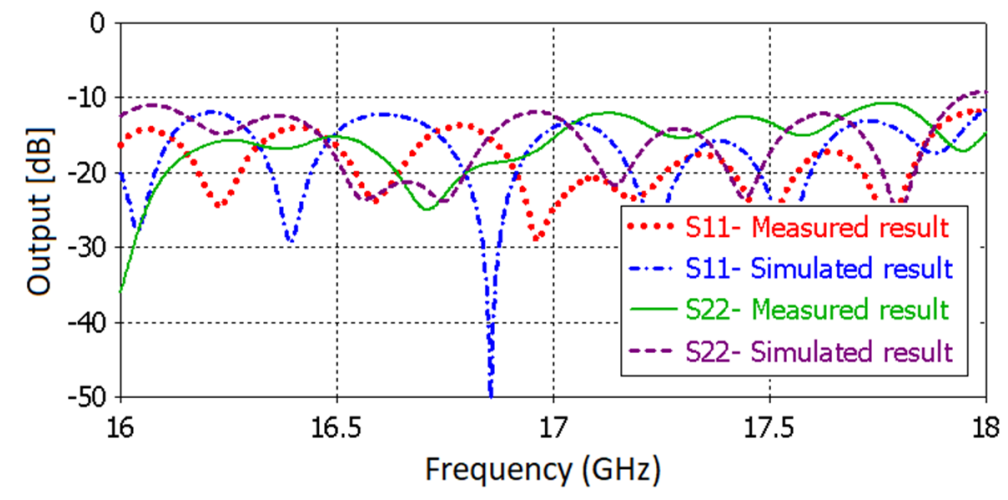

Figure 15. Measured and simulated reflection coefficients of the beam steering antenna system.

The far-field radiation pattern of this antenna system is measured for three different loadings for performance confirmation. $V_{1}$ and $V_{2}$ are the biasing voltages applied to the left and right phase shifters, respectively. First, $V_{1}=0 \mathrm{~V}$ and $V_{2}=20 \mathrm{~V}$ are applied, which steers the null to $-8^{\circ}$, then $V_{1}$ $=20 \mathrm{~V}$ and $V_{2}=10 \mathrm{~V}$ are applied, which steers the null to $5^{\circ}$, and finally $V_{1}=V_{2}=20 \mathrm{~V}$ is applied, which has the null at $0^{\circ}$ and the main lobes at $\pm 25^{\circ}$ which are shown in Figure 16.

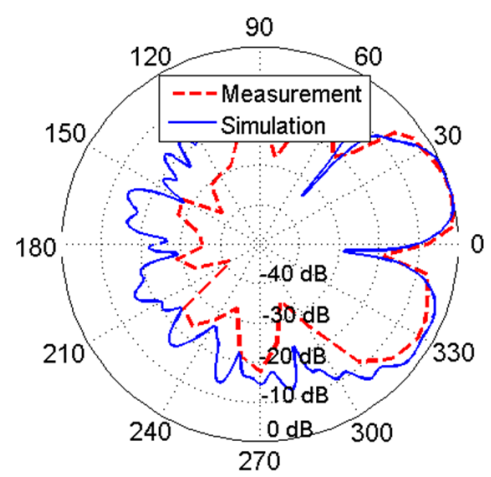

(a)

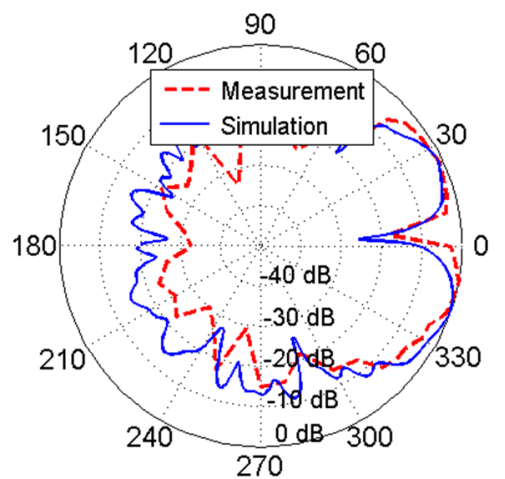

(b)

Figure 16. Cont. 


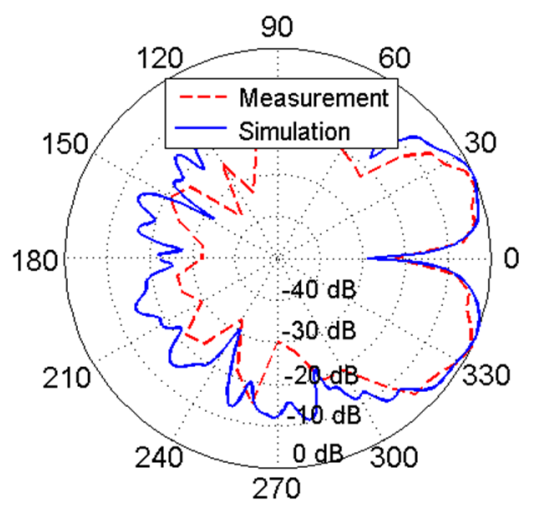

(c)

Figure 16. Measured and simulated far-field radiation pattern of the antenna system while exciting port 1 with (a) $V_{1}=0 \mathrm{~V}$ and $V_{2}=20 \mathrm{~V}$, (b) $V_{1}=20 \mathrm{~V}$ and $V_{2}=10 \mathrm{~V},(\mathbf{c}) V_{1}=V_{2}=20 \mathrm{~V}$.

The co and cross polarization of this antenna system are measured by exciting port 2, terminating port 1 , and applying the $20 \mathrm{~V}$ biasing voltage to both phase shifters. Figure 17 demonstrates the comparison between the measured and simulated results. The measurements are in good agreement with simulations. This antenna system provides a cross polarization better than $20 \mathrm{~dB}$ in the entire beam steering range.

Finally, Figure 18 demonstrates the scanning range of the antenna system. By increasing the biasing voltage of the varactor diodes from 0 to $20 \mathrm{~V}$, a progressive phase shift is provided and applied to the antennas to steer the beam, resulting in $50^{\circ}$ scanning ranges from $-25^{\circ}$ to $25^{\circ}$. Tables 3 and 4 present a comparison between seven recent antenna systems and our proposed design in terms of gain, phase shifter type, polarization, bandwidth, scan range, and number of antenna elements. As is shown, the proposed system in this paper provides a fairly wide scan range and good gain despite the fact that only two antenna elements are used when compared to other systems, which use four antennas.

The antenna efficiency represents the ratio between the total co-polarized radiated power to the input power accepted by the system. This calculation provides an antenna efficiency of $78.89 \%$ at the mid-band frequency of $17 \mathrm{GHz}$ which demonstrates a very good performance of the proposed beam steering system.

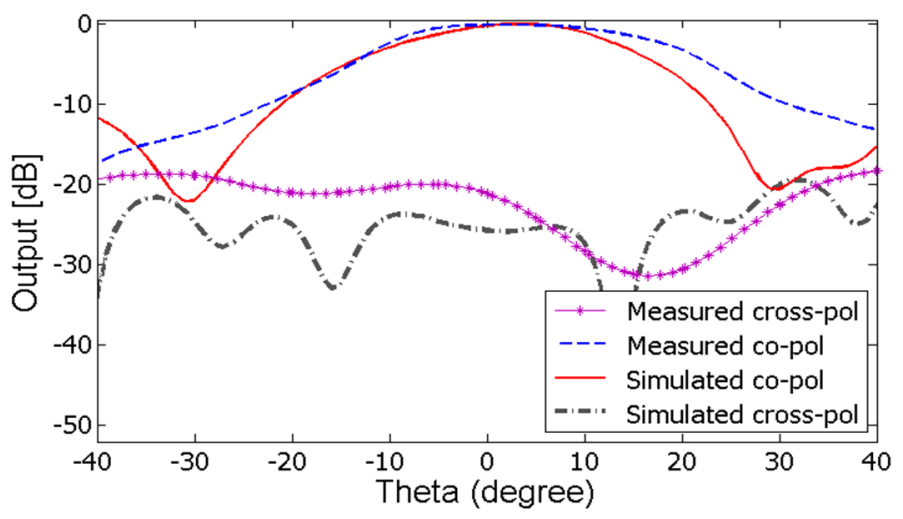

Figure 17. Co-pol and cross pol of the beam steering antenna system when exciting port 2 and applying $V_{1}=V_{2}=20 \mathrm{~V}$ at mid-band frequency of $17 \mathrm{GHz}$. 


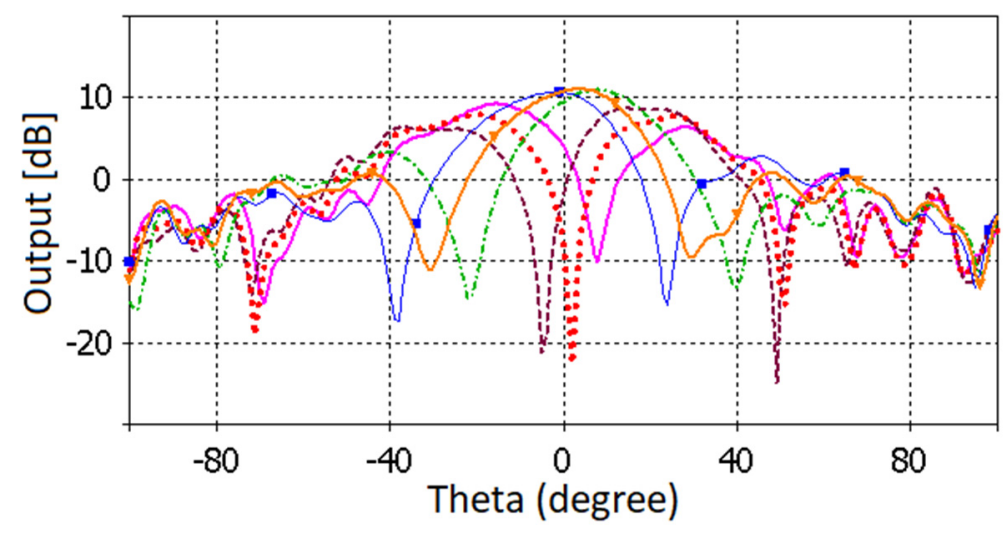

Figure 18. $50^{\circ}$ scan range provided by changing the biasing voltage of the varactor diodes from $0 \mathrm{~V}$ to $20 \mathrm{~V}$.

Table 3. Comparison of seven recent beam steering antenna systems with our design in terms of phase shifter type, bandwidth, and number of elements.

\begin{tabular}{llll}
\hline Antenna System & Number of Antenna Elements & Phase Shifter/Mode & Bandwidth (GHz) \\
\hline$[2]$ & Four & PIN diode/variable & $9.88-10.2$ \\
{$[3]$} & Four & Nolan matric/fixed & $12.25-12.75$ \\
{$[4]$} & Four & Butler matrix/fixed & $27-29$ \\
{$[5]$} & One & CSRR/fixed & $1.98-2.05$ \\
{$[12]$} & One & PIN diode/fixed & $2.8-4.8$ \\
{$[15]$} & Four & $4 \times 4$ Butler matrix/fixed & $23-27$ \\
{$[16]$} & Four & Metal-insulator-metal Varactor/variable & $7-8.4$ \\
Our work & Two & Varactor diode/variable & $16-18$ \\
\hline
\end{tabular}

Table 4. Comparison of seven recent beam steering antenna systems with our design in terms of gain, scan range, and polarization.

\begin{tabular}{llll}
\hline Antenna System & Gain [dBi] & Scan Angle (degree) & Polarization \\
\hline$[2]$ & 15 & $\begin{array}{l}-30 \text { to }+30 \\
\text { Port } 1 /-5.3 \text { to }-15.3\end{array}$ & Linear \\
& & $\begin{array}{l}\text { Port } 2 / 28.7 \text { to } 38.3 \\
\text { Port } 3 / 6.9 \text { to } 16.2\end{array}$ \\
{$[3]$} & Not measured & Port $4 /-27.7$ to -40.7 & Linear \\
& & -35 to +35 & \\
{$[4]$} & 11 & -51 to +48 & Linear \\
{$[5]$} & Not measured & Various in different frequencies. & Linear \\
{$[12]$} & 5.47 & -25 to +25 & Linear \\
{$[15]$} & $8.7-11.7$ & -30 to +30 & Linear \\
{$[16]$} & 13 & -25 to +25 & Linear \\
Our work & 10.7 & & \\
\hline
\end{tabular}

\section{Conclusions}

A substrate integrated waveguide beam steering antenna system is presented for $\mathrm{Ku}$-band applications. The system uses two reflection-type variable phase shifters, a 3-dB coupler with additional phase transition for creating sum or difference patterns, and two Vivaldi antennas. The entire structure is designed on a single substrate layer which makes it compact, low loss, and low profile. Four varactor diodes are used as electrical steering control elements. Experimental results are in good agreement with simulations, thus verifying the design approach.

Author Contributions: S.S.H. and J.B. conceived the initial designs of the phase shifters, Vivaldi antennas, coupler and $90^{\circ}$ phase transition. S.S.H. designed the circuits and experiments, performed the experiments and wrote the first draft of the paper, which both authors finalized.

Funding: This research received no external funding. 
Conflicts of Interest: The authors declare no conflicts of interest.

\section{References}

1. Ding, Y.; Wu, K. Varactor-tuned substrate integrated waveguide phase shifter. In Proceedings of the 2011 IEEE MTT-S International Microwave Symposium, Baltimore, MA, USA, 5-10 June 2011; pp. 1-4.

2. Errifi, H.; Baghdad, A.; Badri, A.; Sahel, A. Electronically reconfigurable beam steering array antenna using switched line phase shifter. In Proceedings of the 2017 International Conference on Wireless Networks and Mobile Communications (WINCOM), Rabat, Morocco, 1-4 November 2017; pp. 1-6.

3. Djerafi, T.; Fonseca, N.J.G.; Wu, K. Planar Ku-band $4 \times 4$ Nolen matrix in SIW technology. IEEE Trans. Microw. Theory Tech. 2010, 58, 259-266. [CrossRef]

4. Khattak, M.K.; Salman Khattak, M.; Rehman, A.; Lee, C.; Han, D.; Park, H.; Kahn, S. A flat, broadband and high gain beam-steering antenna for 5G communication. In Proceedings of the 2017 International Symposium on Antennas and Propagation (ISAP), Phuket, Thailand, 30 October-2 November 2017; pp. 1-2.

5. Cao, W.; Xiang, Y.; Zhang, B.; Liu, A.; Yu, T.; Guo, D. A low-cost compact patch antenna with beam steering based on CSRR-loaded ground. IEEE Antennas Wirel. Propag. Lett. 2011, 10, 1520-1523. [CrossRef]

6. Bousbia, L.; Ould-Elhassen, M.; Mabrouk, M.; Ghazel, A. New synthesis of tunable filter and phase shifter used for phased array antennas applications. In Proceedings of the 2014 International Conference on Multimedia Computing and Systems (ICMCS), Marrakech, Morocco, 14-16 April 2014; pp. 1348-1353.

7. Ma, S.; Yang, G.-H.; Meng, F.-Y.; Ding, X.-M.; Zhang, K.; Fu, J.-H.; Wu, Q. Electrically tunable array antenna with beam steering from backfire to endfire based on liquid crystal miniaturized phase shifter. In Proceedings of the 2016 IEEE Conference on Electromagnetic Field Computation (CEFC), Miami, FL, USA, 13-16 November 2016; p. 1.

8. Zheng, Y.; Saavedra, C.E. Full $360^{\circ}$ vector-sum phase-shifter for microwave system applications. IEEE Trans. Circuits Syst. I Regul. Pap. 2009, 57, 752-758. [CrossRef]

9. Asoodeh, A.; Mojtaba, A. A full $360^{\circ}$ vector-sum phase shifter with very low RMS phase error over a wide bandwidth. IEEE Trans. Microw. Theory Tech. 2012, 60, 1626-1634. [CrossRef]

10. Peng, Z.; Ran, L.; Li, C. A K-band portable FMCW radar with beamforming array for short-range localization and vital-Doppler targets discrimination. IEEE Trans. Microw. Theory Tech. 2017, 65, 3443-3452. [CrossRef]

11. Sellal, K.; Talbi, L.; Nedil, M. Design and implementation of a controllable phase shifter using substrate integrated waveguide. IET Microw. Antennas Propag. 2012, 6, 1090-1094. [CrossRef]

12. Muneer, B.; Qi, Z.; Xu, S. A broadband tunable multilayer substrate integrated waveguide phase shifter. IEEE Microw. Wirel. Compon. Lett. 2015, 25, 220-222. [CrossRef]

13. Sbarra, E.; Marcaccioli, L.; Gatti, R.V.; Sorrentino, R. Ku-band analogue phase shifter in SIW technology. In Proceedings of the 2009 European Microwave Conference (EuMC), Rome, Italy, 29 September-1 October 2009; pp. 264-267.

14. Formiga Mamedes, D.; Esmaeili, M.; Bornemann, J. K-band substrate integrated waveguide variable phase shifter. In Proceedings of the 2016 10th European Conference on Antennas and Propagation (EuCAP), Davos, Switzerland, 10-15 April 2016; pp. 1-4.

15. Park, Z.; Lin, J. A beam-steering broadband microstrip antenna for noncontact vital sign detection. IEEE Antennas Wirel. Propag. Lett. 2011, 10, 235-238. [CrossRef]

16. Ala-Laurinaho, J.; Karttunen, A.; Räisänen, A.V. A mm-wave integrated lens antenna for E-band beam steering. In Proceedings of the 2015 9th European Conference on Antennas and Propagation (EuCAP), Lisbon, Portugal, 13-17 April 2015; pp. 1-2.

17. Yao, Y.-L.; Zhang, F.-S.; Zhang, F. A new approach to design circularly polarized beam-steering antenna arrays without phase shift circuits. IEEE Trans. Antennas Propagat. 2018, 66, 2354-2364. [CrossRef]

18. Bartlett, C.; Salem Hesari, S.; Bornemann, J. End-fire substrate integrated waveguide beam-forming system for 5G applications. In Proceedings of the 2018 18th International Symposium on Antenna Technology and Applied Electromagnetics (ANTEM), Waterloo, ON, Canada, 19-22 August 2018; pp. 1-4.

19. Nikfalazar, M.; Mehmood, A.; Sohrabi, M.; Mikolajek, M.; Wiens, A.; Maune, H.; Kohler, C.; Binder, J.R.; Jakoby, R. Steerable dielectric resonator phased-array antenna based on inkjet-printed tunable phase shifter with BST metal-insulator-metal varactors. IEEE Antennas Wirel. Propag. Lett. 2016, 15, 877-880. [CrossRef] 
20. Kordiboroujeni, Z.; Bornemann, J.; Sieverding, T. Mode-matching design of substrate-integrated waveguide couplers. In Proceedings of the 2012 Asia-Pacific Symposium on Electromagnetic Compatibility, Singapore, 21-24 May 2012; pp. 701-704.

21. Kordiboroujeni, Z.; Bornemann, J. Design of substrate integrated waveguide components using mode-matching techniques. In Proceedings of the 2015 IEEE MTT-S International Conference on Numerical Electromagnetic and Multiphysics Modeling and Optimization (NEMO), Ottawa, ON, Canada, 11-14 August 2015; pp. 1-3.

22. Kordiboroujeni, Z.; Bornemann, J. Designing the width of substrate integrated waveguide structures. IEEE Microw. Wirel. Compon. Lett. 2013, 23, 518-520. [CrossRef]

23. Skyworks. SMV2201-SMV2205 Series: Surface Mount, 0402 Silicon Hyperabrupt Tuning Varactor Diodes Data Sheet. 2012. Available online: https://www.google.com/url?sa=t\&rct=j\&q=\&esrc=s\&source=books\& cd=1\&ved=2ahUKEwih-pbo7cXkAhVVeXAKHboTAykQFjAAegQIABAC\&url=http\%3A\%2F\%2Fwww. skyworksinc.com\%2Fuploads\%2Fdocuments\%2F201953A.pdf\&usg=AOvVaw02zMwJrKKzwrIhnLSz5yfD (accessed on 26 July 2019).

24. Locke, L.S.; Bornemann, J.; Claude, S. Substrate integrated waveguide-fed tapered slot antenna with smooth performance characteristics over an ultra-wide bandwidth. ACES J. 2013, 28, 454-462.

25. Salem Hesari, S.; Bornemann, J. Frequency-selective substrate integrated waveguide front-end system for tracking applications. IET Microw. Antennas Propag. 2018, 12, 1620-1624. [CrossRef]

26. Balanis, C.A. Antenna Theory-Analysis and Design, 3rd ed.; Wiley: New York, NY, USA, 2005.

27. Cheng, Y.; Hong, W.; Wu, K. Novel substrate integrated waveguide fixed phase shifter for 180-degree directional coupler. In Proceedings of the 2007 IEEE/MTT-S International Microwave Symposium, Honolulu, HI, USA, 3-8 June 2007; pp. 189-192.

28. CST. Application NoteCST STUDIOSUITE ${ }^{\mathrm{TM}}$ 2006B: Antenna Arrays. 2012. Available online: https://www.google.com/url? sa $=$ t\&rct=j\&q=\&esrc=s\&source=web\&cd=2\&ved=2ahUKEwjRlru778XkAhWYHXAKHeFKDusQFjABegQIBhAC\& url=https $\% 3 \mathrm{~A} \% 2 \mathrm{~F} \% 2$ Fperso.telecom-paristech.fr\%2Fbegaud\%2Fintra\%2FCST_ANTENNAARRAY.pdf\&usg= AOvVaw0UxlbJD3SHsaJahJQ2HgwM (accessed on 26 July 2019).

(C) 2019 by the authors. Licensee MDPI, Basel, Switzerland. This article is an open access article distributed under the terms and conditions of the Creative Commons Attribution (CC BY) license (http://creativecommons.org/licenses/by/4.0/). 